\title{
Evaluation of thermotolerant rhizobacteria for multiple plant growth promoting traits from pigeonpea rhizosphere
}

\author{
Gurmeet Kaur $^{1^{*}}$ and Veena Khanna ${ }^{2}$ \\ ${ }^{1}$ Department of Microbiology, Punjab Agricultural University, Ludhiana - 141001 (Punjab), INDIA \\ ${ }^{2}$ Department of Plant Breeding and Genetics, Punjab Agricultural University, Ludhiana - 141001 (Punjab), INDIA \\ *Corresponding author. E-mail: gk45332@gmail.com
}

Received: July 15, 2016; Revised received: February 4, 2017; Accepted: April 30, 2017

\begin{abstract}
PGPR strains exhibiting optimum functional traits at high temperature and are compatible with Rhizobium can be used in pigeonpea as biofertilizer. A total of 45 rhizobacterial isolates were isolated from 13 different locations of pigeonpearhizospheric soil of Punjab. Out of the 45 isolates, 5 isolates selected on the basis of maximum growth at $30^{\circ} \mathrm{C}$ and $40^{\circ} \mathrm{C}$ were morphologically and biochemically characterized, belonging to genera Pseudomonas (P-6, P-9) and Bacillus (P-30, P-31, P-32). Selected isolates were further evaluated for the production of IAA, GA, $\mathrm{SA}$ and flavonoids. IAA production was estimated in the range from $0.45-25.13 \mu \mathrm{g} / \mathrm{ml}$ and $4.62-34.34 \mu \mathrm{g} / \mathrm{ml}$ in the presence of tryptophan at 30 and $40^{\circ} \mathrm{C}$ respectively. Maximum gibberellic acid production was recorded with $\mathrm{P}-30$ $(108.99 \mu \mathrm{g} / \mathrm{ml}$ and $112.12 \mu \mathrm{g} / \mathrm{ml})$ at 30 and $40{ }^{\circ} \mathrm{C}$ respectively. Similarly maximum salicylic acid was also estimated with P-30 $(157.2 \mu \mathrm{g} / \mathrm{ml})$ followed by P-31 $(141.0 \mu \mathrm{g} / \mathrm{ml})$ at $40{ }^{\circ} \mathrm{C}$. All the isolates were also found to produce flavonoids ranged from $2.98-4.40 \mu \mathrm{g} / \mathrm{ml}$ at $40{ }^{\circ} \mathrm{C}$. Isolates P-30, P-31 showed superior production of growth hormones and flavonoid-like compounds can further be tested under the field conditions to enhance growth and yield of pigeonpea.
\end{abstract}

Keywords: Pigeonpea, PGPR, Rhizobium, Rhizobacteria

\section{INTRODUCTION}

Pigeonpea (Cajanuscajan L.) is one of the important pulse crop and a very popular food of developing tropical countries. It is a versatile, stress-tolerant and nutritious grain legume, possessing traits of value for enhancing the sustainability of dry sub-tropical and tropical agricultural systems as the seed is eaten as a green vegetable and dry pulse and is an important source of protein, vitamin $\mathrm{B}$, carotene and ascorbic acid (Odney, 2007 and Choudhary et al., 2013). The pods and foliage of the plant are used as livestock forage and fodder, the crop is cultivated as a green manure, and its woody stem is used as fuel and construction material (Mallikarjuna et al., 2011). In Punjab pigeonpea occupied an area of 2.6 thousand hectares with a production of 2.39 thousand tonnes during the year 2014-15. The average yield was 9.18 quintals per hectare (Anonymous, 2016).

Pigeonpea is an important $\mathrm{N}$-fixing crop in association with Rhizobium sp. and maintains soil fertility. The high soil temperature greatly effect legume-Rhizobium symbiosis in pigeonpea but it is relatively drought tolerant crop performs well in temperature range of 25-35 ${ }^{\circ} \mathrm{C}$ and can also survive at $45{ }^{\circ} \mathrm{C}$. The plant growth promoting rhizobacteria (PGPR) facilitate plant growth and development with wide variety of direct and indirect mechanisms under stress and non-stress conditions (Nadeem et al., 2014). The direct promotion by PGPR either provide the plant with a plant growth promoting substances synthesized by the bacterium or facilitate the uptake of certain plant nutrients from the environment. The indirect promotion of plant growth occurs when PGPR lessen or prevent the deleterious effect of one or more phytopathogenic microorganisms. Keeping this in view present study deals with isolation, characterization and screening of high temperature tolerant rhizobacterial isolates for their multiple plant growth promoting traits from rhizosphere of pigeonpea crop.

\section{MATERIAL AND METHODS}

Isolation of rhizobacteria: Isolates of rhizobacteria were isolated from 13 different locations of pigeonpearhizospheric soil samples. One gram of soil was suspended in sterile water blanks. Pour plating was done on Nutrient agar mediun for Bacillus and Serratia,on YEMA medium for Rhizobium and on King's B medium (King et al., 1954) for Pseudomonas by standard microbiological techniques. 17 rhizobacterial isolates were isolated from King's B medium, 23 from nutrient agar medium and 5 from YEMA medium. The isolates were grown at $30^{\circ} \mathrm{C}$ and $40^{\circ} \mathrm{C}$ in respective media and growth in terms of optical density was recorded at $600 \mathrm{~nm}$. Five isolates showing maximum growth both at $30{ }^{\circ} \mathrm{C}$ and $40{ }^{\circ} \mathrm{C}$ were selected for 


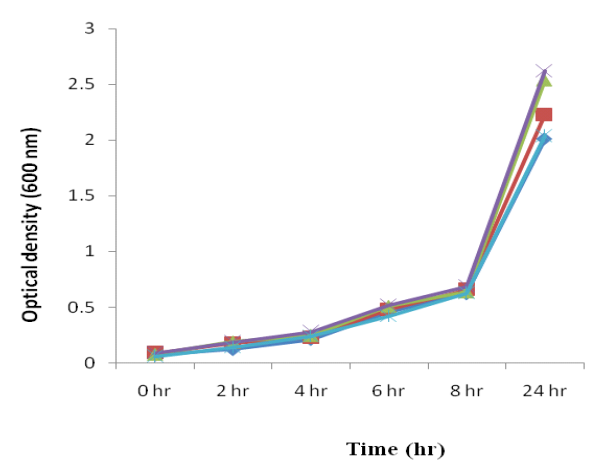

Fig. 1. Growth curve of rhizobacterial isolates at $30{ }^{\circ} \mathrm{C}$.

further analysis.

Biochemical characterization of rhizobacteria: Biochemical characterization of bacterial isolates was done on the basis of Gram reaction, catalase production, starch hydrolysis, nitrate reduction and methyl red test as per the standard methods (Cappuccino and Sherman., 1992 and Holt et al., 1994).

IAA and Gibberellic acid production: Characterization of isolates for the production of IAA and Gibberellic acid (GA) was determined as per the method given by Gordon and Weber (1951) and Borrow et al. (1955) respectively.

Production of salicylic acid: Salicylic acid (SA) production of isolates was done as per the method described by Meyer and Abdallagh (1978).

Flavonoid production: Total Flavonoid content was estimated spectrophotometrically (Zhishen et al., 1999). The extracted material was further processed by thin layer chromatography (TLC) by method given by Parmar and Dadarwal (1999).

\section{RESULTS AND DISCUSSION}

Isolation and Characterization: A total of 45 isolates of rhizobacteria were isolated from various pigeonpearhizospheric soil samples taken from 13 different locations of Punjab. The isolates P-1 to P-17 from King's B medium showed the characteristic yellowishgreen pigmentation. Two isolates $\mathrm{P}-18$ and $\mathrm{P}-19$ from nutrient agar medium with entire margin produced red colour pigmentation, whereas the other isolates P-20 to P-40 showed predominantly off-white to creamish in colour colonies. The isolates P-41 to P-45 from YEMA medium showed gummy colonies. On the basis of cultural morphological and biochemical tests, these were tentatively assigned to genera Pseudomonas, Serratia, Bacillus, and Rhizobium (Table 1).

The growth in terms of optical density recorded at $30^{\circ}$ $\mathrm{C}$ and $40{ }^{\circ} \mathrm{C}$ showed that rhizobacterial isolates attained exponential growth at both $30^{\circ} \mathrm{C}$ and $40^{\circ} \mathrm{C}$ when incubated for $24 \mathrm{hr}$. Isolates P-6, P-9, P-30, P-31 and P -32 showed higher growth at $40^{\circ} \mathrm{C}$ (Fig. 1\&2). Nehra et al. (2007) reported four pigeonpearhizobial strains (HR-3, HR-6, HR-10 and HR-12) which were temperature tolerant, highly efficient for all the symbiotic

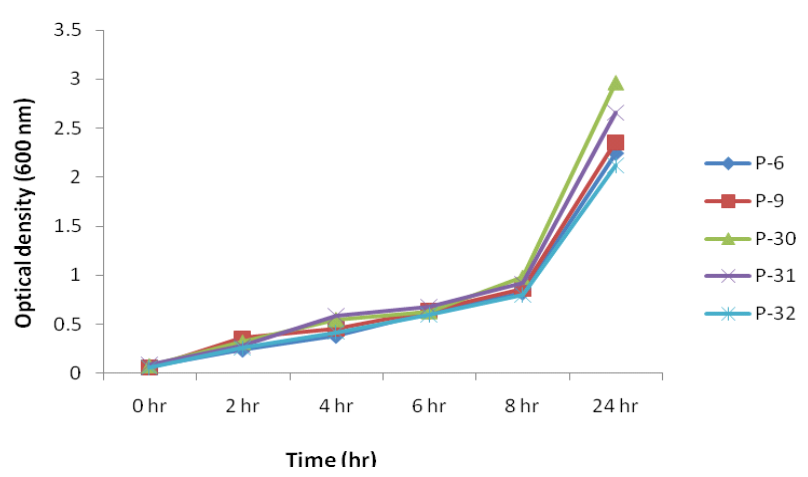

Fig. 2. Growth curve of rhizobacterial isolates at $40^{\circ} \mathrm{C}$.

parameters and thus having the potential to be used as bio-inoculants in North-Western regions of India. Srivastava et al. (2008) isolated a thermotolerant Pseudomonas putida NBRI0987 from drought affected rhizosphere of chickpea. Kaur and Khanna (2013) reported that out of 15 rhizobial strains isolated from pigeonpearhizosphere, four most temperature tolerant strains (LAR-2, LAR-3, LAR-4 and LAR-8) exhibited growth at $45^{\circ} \mathrm{C}$

Indole acetic acid production: The auxin, IAA is an important phytohormone produced by PGPR. It may function as an important signal molecule in the regulation of plant development. IAA production ranged from $1.24-16.17 \mu \mathrm{g} / \mathrm{ml}$ in presence of tryptophan after 3 days of incubation and increased to 0.45 to $25.13 \mu \mathrm{g} /$ $\mathrm{ml}$ after 5 days of incubation at $30^{\circ} \mathrm{C}$ whereas at $40{ }^{\circ} \mathrm{C}$ IAA production ranged from $1.04-24.88 \mu \mathrm{g} / \mathrm{ml}$ in presence of tryptophan after 3 days of incubation and increased to $4.62-34.34 \mu \mathrm{g} / \mathrm{ml}$ after 5 days of incubation. IAA production by potent rhizobacterial isolates was more at $40^{\circ} \mathrm{C}$ than at $30^{\circ} \mathrm{C}$ (Table 2). Ali et al. (2009) reported that isolate JGP-46 was the best producer of indole acetic acid followed by RMP-6 and AKM-P6 in

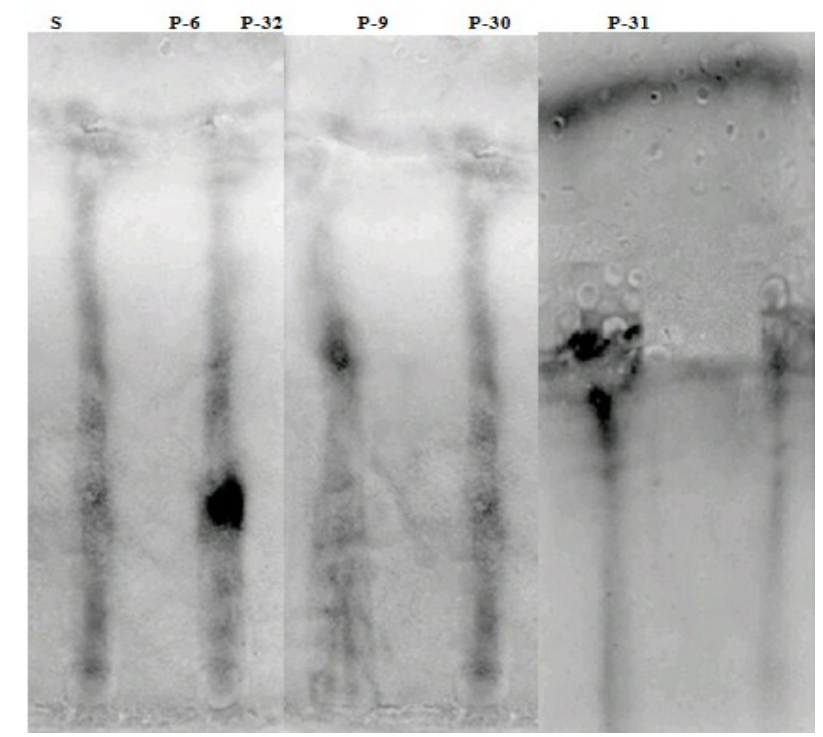

Plate 1. TLC analysis of flavonoid like compounds produced by rhizobacteria. 
Gurmeet Kaur and Veena Khanna / J. Appl. \& Nat. Sci. 9 (2): 920 - 923 (2017)

Table 1. Cultural, morphological and biochemical characteristics of rhizobacterial isolates.

\begin{tabular}{lcccc}
\hline Characteristics & Bacillus sp. & Rhizobium sp. & Pseudomonas sp. & Serratia sp. \\
\hline Gram's reaction & + ve & - ve & - ve & -ve \\
Shape & Rods & Rods & Rods & Rods \\
Pigment & - & + & + & + \\
Pigment colour & White & Whitish pink & Fluorescent green & Red \\
Starch hydrolysis & + & + & + & + \\
Catalase production & + & + & - & + \\
Methyl red test & - & - & + & - \\
Nitrate reduction & + & + & & + \\
\hline
\end{tabular}

Table 2. IAA and Gibberellic acid production at $30^{\circ} \mathrm{C}$ and $40^{\circ} \mathrm{C}$.

\begin{tabular}{|c|c|c|c|c|c|c|}
\hline \multirow{2}{*}{$\begin{array}{l}\text { Rhizobacterial } \\
\text { Isolates }\end{array}$} & \multicolumn{2}{|c|}{ IAA equivalent $(\mu \mathrm{g} / \mathrm{ml})$ at $30^{\circ} \mathrm{C}$} & \multicolumn{2}{|c|}{ IAA equivalents $(\mu \mathrm{g} / \mathrm{ml})$ at $40^{\circ} \mathrm{C}$} & \multicolumn{2}{|c|}{ Gibberellic acid production } \\
\hline & L -TRP(-) & L-TRP (+) & L -TRP(-) & L-TRP (+) & $30^{\circ} \mathrm{C}$ & $40{ }^{\circ} \mathrm{C}$ \\
\hline P-6 & 6.24 & 18.08 & 10.11 & 21.32 & 96.85 & 82.47 \\
\hline P-9 & 10.92 & 20.96 & 14.88 & 30.01 & 100.08 & 102.69 \\
\hline $\mathrm{P}-30$ & 11.02 & 25.13 & 14.28 & 33.25 & 108.99 & 112.12 \\
\hline P-31 & 10.98 & 19.58 & 12.14 & 34.34 & 101.48 & 97.76 \\
\hline P-32 & 10.87 & 17.24 & 10.87 & 29.58 & 67.19 & 75.20 \\
\hline
\end{tabular}

Table 3. Salicylic acid and flavonoid production at $30^{\circ} \mathrm{C}$ and $40^{\circ} \mathrm{C}$.

\begin{tabular}{lrccc}
\hline \multirow{2}{*}{ Rhizobacterial Isolates } & \multicolumn{2}{c}{ Salicylic acid production $(\boldsymbol{\mu g} / \mathbf{m l})$} & \multicolumn{2}{c}{ Flavonoid Production $(\boldsymbol{\mu g} / \mathbf{m l})$} \\
\cline { 2 - 5 } & $\mathbf{3 0}^{\circ} \mathbf{C}$ & $\mathbf{4 0}^{\circ} \mathbf{C}$ & $\mathbf{3 0}^{\circ} \mathbf{C}$ & 3.12 \\
\hline P-6 & 90.90 & 134.1 & 2.89 & 3.98 \\
P-9 & 102.20 & 117.6 & 3.77 & 4.40 \\
P-30 & 91.59 & 157.2 & 4.18 & 4.14 \\
P-31 & 124.50 & 141.0 & 4.96 & 2.98 \\
P-32 & 87.20 & 126.9 & 3.01 & ${ }^{\circ} \mathbf{C}$ \\
\hline
\end{tabular}

sorghum under elevated temperature. Bacillus megaterium has been reported to produce IAA at various growth temperatures in tryptophan supplemented medium (Trivedi and Pandey, 2008).

Gibberellic acid production: Gibberellic acid is a very potent hormone whose natural occurrence in plants controls their development, including seed germination, flower induction and fruit expansion (Bhattacharyya et al., 2012). Here too, the five isolates showed higher $\mathrm{GA}$ production at $30^{\circ} \mathrm{C}$, isolate P-30 $(108.99 \mu \mathrm{g} / \mathrm{ml})$ was found to be strong producer of gibberellic acid followed by P-31 (101.48 $\mu \mathrm{g} / \mathrm{ml}), \mathrm{P}$ $9(100.08 \mu \mathrm{g} / \mathrm{ml})$, P-6 $(96.85 \mu \mathrm{g} / \mathrm{ml})$ and P-32 (67.19 $\mu \mathrm{g} / \mathrm{ml})$. At $40{ }^{\circ} \mathrm{C}$ isolate P-30 $(112.12 \mu \mathrm{g} / \mathrm{ml})$ was also found to be potent producer of gibberelllic acid followed by P-9 (102.69 $\mu \mathrm{g} / \mathrm{ml})$, P-31(97.76 $\mu \mathrm{g} / \mathrm{ml})$, P-6 $(82.47 \mu \mathrm{g} / \mathrm{ml})$ and P-32 $(75.20 \mu \mathrm{g} / \mathrm{ml})$ (Table 2). Ali et al. (2009) reported out of five thermotolerant $\left(50{ }^{\circ} \mathrm{C}\right)$ isolates AKM-P6 was the best producer of gibberellic acid in sorghum. Ruchi et al. (2012) also founded gibberellins production in the range of $125-300 \mu \mathrm{g} / \mathrm{ml}$. Mia et al. (2012) reported that increase in seed germination percentage and seedling shoot length were typically gibberellins-like responses.

Salicylic acid production: Salicylic acid production by rhizobacterial isolates has been reported to play an important role in regulation of many physiological processes in plants. At $30{ }^{\circ} \mathrm{C}, \mathrm{P}-31(124.5 \mu \mathrm{g} / \mathrm{ml})$ was maximum producer of salicylic acid, whereas at $40^{\circ}$ C maximum producer was P-30 $(157.2 \mu \mathrm{g} / \mathrm{ml})$ followed by P-31 $(141.0 \mu \mathrm{g} / \mathrm{ml}), \mathrm{P}-6(134.1 \mu \mathrm{g} / \mathrm{ml})$ and P
-32 $(126.9 \mu \mathrm{g} / \mathrm{ml}$ and P-9 $(117.6 \mu \mathrm{g} / \mathrm{ml})$ (Table 3) . Zhang et al., (2002) observed that PGPR produced salicylic acid which induces systemic resistance against blue mold of tobacco. Chakraborty and Tongden, (2005) reported that the heat stress induced membrane injury in plants of Cicer arietinum was significantly reduced by the application of SA, compared to heat acclimatized and untreated control.

Flavonoid production: Potential multi-functional PGPRs including P-6, P-9, P-30, P-31 and P-32 were evaluated for the production of flavonoid-like compounds. The flavonoids secretion by plant roots is fascinating for the multiple roles played in the process of nodulation. Flavonoid production was recorded in the range of $2.98-4.40 \mu \mathrm{g} / \mathrm{ml}$ at $40{ }^{\circ} \mathrm{C}$, maximum producer being P-30 $(4.40 \mu \mathrm{g} / \mathrm{ml})$ followed by P-31 $(4.14 \mu \mathrm{g} /$ $\mathrm{ml})$, P-9 $(3.98 \mu \mathrm{g} / \mathrm{ml})$, P-6 $(3.12 \mu \mathrm{g} / \mathrm{ml})$ and P-32 (2.98 $\mu \mathrm{g} / \mathrm{ml}$ ) (Table 3).

The TLC plates showed a single fluorescent spot in culture supernatant of P-9 and P-31, one spot corresponded with that of the standard naringin and other with lower mobility. However, isolate P-30 exhibited production of two fluorescent spots one equivalent to naringin and other with a lower mobility. However, isolate P-6 and P-32 exhibited none of the fluorescent spots (Plate 1). Parmar and Dadarwal (1999) reported that supernatant extract from Bacillus isolates showed single fluorescent spot equivalent to standard naringin and Pseudomonas isolates showed two fluorescent spots with lower mobility corresponded to standard naringin. 


\section{Conclusion}

The study indicates that there are several beneficial traits in rhizobacterial strains that could improve plant growth. Rhizobacterial isolate P-30 was most favourable for IAA production $(25.13 \mu \mathrm{g} / \mathrm{ml})$ and gibberellic acid production $(108.99 \mu \mathrm{g} / \mathrm{ml})$ whereas, P-31 was most favourable for salicylic acid production (124.50 $\mu \mathrm{g} / \mathrm{ml})$ and fllavonoid production $(4.96 \mu \mathrm{g} / \mathrm{ml})$ at temperature $30{ }^{\circ} \mathrm{C}$. At temperature $40{ }^{\circ} \mathrm{C}$, rhizobacterial isolates P-31 was most promising for IAA production $(34.34 \mu \mathrm{g} / \mathrm{ml})$ and salicylic acid production $(157.2 \mu \mathrm{g} /$ $\mathrm{ml}$ ), whereas P-30 was found most promising for gibberelllic acid prodution $(112.12 \mu \mathrm{g} / \mathrm{ml})$ and flavonoid production $(4.40 \mu \mathrm{g} / \mathrm{ml})$. So, we consider the bacterial strains P-30 and P-31 most feasible to be used as inoculant for plant growth improvement.

\section{REFERENCES}

Anonymous (2016). Package and practice for kharif crops. Pp. 62. Punjab Agricultural University, Ludhiana.

Ali, S.Z., Sadhya, V., Grover, M., Kishore, N., Rao, L. V. and Venkateswarlu, B. (2009). Pseudomonas sp. strain AKM-P6 enhances tolerance of sorghum seedlings to elevated temperatures. Biol. Fertil. Soils., 46: 45-55

Borrow, A., Brain, P. W., Chester, V. E., Curtis, P. J., Hemming, H. G., Henehan, C., Jeffereys, E. G., Lloyd, P. B., Nixon, I. S., Norris, G. L. F. and Radley, M. (1955). Gibberellic acids a metabolic product of the fungus Gibberellafujikuroi some observations on its production and isolation. J Sci Food Agric., 6: 340-48

Bhattacharyya, P. N. and Jha, D. K. (2012). Plant growth promoting rhizobacteria: emergence in agriculture. World J. Microbiol. Biotechnol., 28: 1327-1350

Cappuccino, J. C. and Sherman, N. (1992). Microbiology: A Laboratory Manual Pp.125-79. Academic distributors, New York.

Chakraborty, U. and Tongden, C. (2005). Evaluation of heat accumulation and salicylic acid treatments as potent inducers of thermotolerance in Cicerarietinum L. Curr. Sci., 89: 384-89

Choudhary, A. K., Kumar, S., Patil, B. S., Bhat, J. S., Sharma, M., Kemal, S., Ontagodi, T. P., Datta, S., Patil, P., Chaturvedi, S. K., Sultana, R., Hedge, V. S., Choudhary, S., Kamannavar, P. Y. and Vijayakumar, A. G.(2013). Narrowing yield gaps through genetic improvement for Fusarium wild resistance in three pulse crops of the semi-arid tropics. Subbarao J Breed Genet., 45(3): 341-70

Gordon, A. S. and Weber, R. P. (1951). Calorimetric estimation of Indole acetic acid. Pl Physiol., 25: 192-95

Holt, P. S., Burh, R. J., Cunnigham, D.L. and Porter, R. E. (1994). Effect of two different molting procedures on Salmonellaenteritis infection. Poult Sci., 73: 1267-75
Kaur, S. and Khanna, V. (2013). Effect of temperaturetolerant rhizobial isolates as PGPR on nodulation, growth and yield of Pigeonpea. J Food Legumes, 26: 80 $-83$

King, E. O., Ward, M. K. and Raney, D. E. (1954). Two simple media for the demonstration of pyocyanin and fluorecein. J Lab Clin Med., 44:301-07

Mallikarjuna, N., Saxena, K. B. and Jadhav, D. R. (2011). Cajanus. In: Kole, C. (ED.), Wild crop relatives: Genomic and breeding resources, legume crops and forages. Springer-Verlag, Berlin, Heidelberg Pp. 21-33

Meyer, J. M. and Abdallah, M. A. (1978). The fluorescent pigment of Pseudomonas fluorescence: biosynthesis, purification and physicochemical properties. J Gen Microbiol., 107:319-28

Mia, M. A. B., Shamsuddin, Z. H. and Mahmood, M. (2012). Effects of rhizobia and plant growth promoting rhizobacteria inoculation on germination and seedling vigor of lowland rice. Afr J Biotechnol., 11: 3758-65

Nadeem, S. M., Ahmad, M., Zahir, A. Z., Javaid, A. and Ashraf, M. (2014). The role of mycorrhizae and plant growth promoting rhizobacteria (PGPR) in improving crop productivity under stressful environments. Biotechnol adv, 32: 429-48

Nehra, K., Yadav, A.S., Sehrawat, A.R. and Vashisha, R.K. (2007). Characterization of heat resistant mutant strains of Rhizobium sp. (CajanuscajanL.) for growth, survival and symbiotic properties. Ind J Microbiol4: 329-35.

Odney., (2007). The potential of pigeonpea (Cajanuscajan (L.) Millsp.) in Africa. Natural Resources Forum. 31: 297-05.

Parmar, N. and Dadarwal, K.R. (1999). Stimulation of nitrogen fixation and induction of flavonoid like compounds by rhizobacteria . J ApplMicrobiol.86: 36-44.

Ruchi, K.R., Kumar, A., Patil, S., Thapa, S. and Kaur, M. (2012). Evaluation of plant growth promoting attributes and lytic enzyme production by fluorescent Pseudomonas diversity associated with apple and pear. Int $J$ Sci Res Pub 2: 2250-3153.

Srivastava, S., Yadav, A., Mishra, S., Chaudary, V. and Srivastava, C.S. (2008) Effect of high temperature on Pseudononasputida NBRI0987 biofilm formation and expression of stress sigma factors RpoS. Curr Microbial 56: 453-457.

Trivedi, P., Anita, P., Lok, M. and Palni, S. (2008). In vitro evaluation of antagonistic properties of Pseudomonas corrugata. Microbiol Res 163: 329-36.

Zhang, S., Moyne, A., Reddy, M.S. and Kloepper J.W. (2002). The role of salicylic acid in induced systemic resistance elicited by plant growth-promoting rhizobacteria against blue mold of tobacco. Biol Control 25 (3):288-96.

Zhishen, J., Mengcheng, T. and Jianming, W. (1999). The determination of flavonoid contents in mulberry and their scavenging effects on superoxide radicals. Food Chem. 64: 555-59. 